food débris that had passed from the osophagus through the ref perforation into the trachea. There were no metastases. In this case there was no obstruction to the passage of food along the oesophagus into the stomach at any time during the patient's illness, although the tender infiltrated thyroid gland made swallowing painful. The particularly prominent symptoms were due to the bilateral abductor palsy of the vocal cords by the involvement of the recurrent laryngeal nerves in the extension of the growth from the cesophagus into the thyroid gland. The fatal termination of the case was due to the perforation of the trachea by the growth with the subsequent production of a septic broncho-pneumonia

I wish to express my thanks to Dr. Eustace Smith and to Dr. E. Clifford Beale, under whose care these patients were, for their courtesy in allowing me to report them, and also to Dr. J. J: Perkins and Dr. George E. Rennie, formerly patho. logists to the haspital, for the use of the post-mortem records. Birmingham.

\section{THE TREATMENT OF ATONIC DILATATION OF THE STOMACH BY MEANS OF HIGH-FREQUENCY CURRENTS.} By A L EX A N D E R C R O M B I E, M.D. EDIN., AND

\section{T. J. BOKENHAM, M.R.C.S. ENG., L.R.C.P. LOND.}

THE highly unsatisfactory and uncertain results of treatment in atonic dilatation of the stomach by the methods ordinarily in use led us to try the effect of rapid oscillatory currents of high voltage in cases of this nature. The results have been gratifying in the highest degree. The details of the 17 cases we give will show what their character wasi. e., that they were cases of non-obstructive dilatation of the stomach of a duration varying from a few months to 15 years, marked by dyspeptic symptoms of greater or less severity and accompanied by neurasthenia of a more or less pronounced kind, from mere "loss of nerve" to profound depression and complete nervous breakdown. In three of our cases the condition seemed to depend for causation on mental strain and the dilatation of the stomach to be secondary, but how far previously unnoticed dilatation may have contributed to the result it is impossible for us to say. In all the others the dilatation was probably primary and due to causes obviously capable of producing this condition, and the neurasthenic symptoms followed as the effect of the defective digestion, malnutrition, and auto-intoxication consequent on the dilatation. That this was the true relationship is rendered probable by the fact that on the reduction of the size of the stomach and the improvement in digestion the neurasthenia disappeared, but in one case (Case 12), in which the reduction of the stomach to its normal dimensions was not followed by improved digestion, there was no amelioration of the neurasthenic symptoms and, as is well known, there may be a dilated stomach without any neurasthenia provided the digestion is performed in a fairly satisfactory manner in spite of the dilatation. Moreover, we were repeatedly in a position to demorstrate in the most conclusive manner that the primary effect of the treatment is to reduce the size of the stomach. To demonstrate this it is only necessary to mark out carefully on the surface the limits of the stomach before and after the application of the current at any sitting -and to do this correctly requires the ability to distinguish slight differences of tone in the percussion note--and to remember that an organ which is partly filled with gas and partly with fluid does not everywhere give the same percussion note. The tympanitic note elicited at the cardiac is very different from the duller sound towards the pyloric end of the stomach. That this has often been forgotten is shown by the figures of dilated stomachs in some text-books, in which they are represented as not extending to the right of the middle line. In advanced cases when there is a pyloris pouch giving a tympanitic note on percussion and the duodenum and colon are also at the same time dilated and tympanitic some difficulty may be found in delimiting the extension of the stomach in this direction and then the simultaneous use of a binaural stethoscope, placer alternately within and beyond the supposed limits of the stomach, and light tapping with the end of the marking pencil will resolve the difficulty. It often facilitates matters to inflate the stomach by a draught of aerated water to bring out the tympanitic note more clearly. By the exercise of similar care the position of the colon and even of the duodenum can be made out. In most cases a certain amount of displacement of the transverse colon could be detected and in some of those described below there was very distinct intestinal ptosis; this seemed to make no difference in the final result.

Having in this way carefully marked on the surface the limits of the dilated stomach before the application of the electrode, if this is done again immediately after the treatment the stomach will be found to have receded from half to three-quarters of an inch in all directions. This result was invariable, and we know of no effect of any remedial agent in the whole domain of practical medicine which is so certain and so conclusively demonstrable as this retrocession of a dilated stomach on the application of a high-frequency current. This is not accompanied by any altered sensation on the part of the patient who at the time feels nothing, though he is naturally conscious after a few sittings of being "tucked up" as the retrocession of the stomach proceeds and the process of digestion improves. After a number of applications, varying in different cases from 10 to 20, the stomach was found to have assumed its normal position and size and the other parts of the intestinal tract to have returned to their natural relative positions. At the same time, in all but two of our patients the normal process of digestion was restored, but it was considered advisable to continue the dietary regimen for some time longer. There was a short relapse of indigestion in one case and of re-dilatation in another after dietetic indiscretions. In one there was no improvement in digestion owing apparently to a radical fault in the gastric juice (hypochlorhydria), although the stomach remained of normal size. This patient is slowly improving under treatment conducted on general principles and his stomach continued normal in size and position for at least six weeks after the electric treatment was discontinued. Whether the effect in this and the other cases will be permanent, with the necessary precautions as to diet, it is, of course, impossible at present to say, but we venture to assert that such results as we have obtained in 15 of our cases would not have been possible with the means of treatment usually employed in this troublesome condition in the same time and with so little difficulty.

Our experience of this treatment leads us to think that the immediate and possibly the only effect of the high-frequency applications is to give tone directly, or indirectly through the vagus, to the unstriped fibres which constitute the muscular walls of the stomach, and that this "toning up " enables them to contract and to diminish the size of the organ. The improvement in digestion which follows is probably the result of the restoration of a more normal condition of the circulation and blood-supply to the gastric glands, consequent on the return of the stomach to its natural size and position. It is not apparently due to any special stimulation of the gastric glands, because in those cases in which there is a radical fault in the secretion no improvement in this respect follows the reduction of the dimensions of the stomach although the electric treatment is continued. The tone given to the unstriped muscular fibres enables the stomach to empty itself after each meal, and the retention of imperfectly digested food ceases, and with this the absorption of abnormal products of digestion and the consequent symptoms of auto-intoxication and neurasthenia. Further experience may, however, modify this view of the action in such cases of the high-frequency current, an agency of which the potency and mode of action are at present so little known. Besides the (usually) daily application of the kigh-frequency current all these cases were placed on a diet calculated to reduce the difficulties with which a dilated stomach has to deal. The amount of fluid taken with meals was reduced to a minimum, and articles of diet of acknowledged difficulty of digestion were forbidden, but without any reduction in the nutritive value of the dietary. This was the "dry diet" referred to in our cases. The necessary amount of fluid required by the organism was taken in the form of hot water not less than three-quarters of an hour before meals. It will be noticed that this diet had been continued in some instances for some time, in one case six months, with only slight benefit, before the commencement of electrical treatment, and that marked improvement immediately followed 
the use of the high-frequency current, with a practical and so far permanent "cure" in a few weeks. In stout people there was, as a rule, distinct loss of weight during the continuance of the treatment, but the thin and emaciated gained weight steadily. In only one case was it thought advisable to resort to lavage after beginning the treatment.

Technique.-The apparatus employed consisted of a Rhumkorff coil capable of giving a "12-inch spark" with heavy discharge. The interruption of the primary circuit was at first effected by the ordinary vibrating hammer or by a mercury dipping break, but these have for a long time been discarded in favour of the improved Mackenzie Davidson break, as made by Cox, which has for some months past worked excellently and with scarcely any trouble. T'he secondary wires of the coil are led to the inner coats of two Leyden jars of large capacity, which are furnished with adjustable dischargers, after the plan of d'Arsonval, the noise of the discharges being deadened by inclosing the discharging knobs in a glass-lined oak box. The outer coats of these jars are connected through a variable number of turns of thick wire, one of which is led to "earth," the other being connected to the lower coils of an Oudin's resonator. The current used for the treatment is obtained from one of the upper coils of the resonator and it is a very rapidly surging alternating current of high voltage. This current is applied in a variety of ways by means of special electrodes which may be classed as (a) monopolar-brush electrode ; $(b)$ glass or ebonite "condenser" electrodes of various forms and capacity ; and (c) moistened plate electrodes of flexible sheet-lead and of large size. As regards the electrical conditions set up when these different electrodes are used there is considerable difficulty in speaking with certainty, so many factors have to be taken into account while but little is really known about the actual physical conditions.

(a) In the early cases treated the patient was placed on a couch and the region of the stomach was "sprayed" by a brush electrode held at a distance just beyond that at which a direct spark would pass between the electrode and the skin. The effect experienced was described as similar to the dropping of a shower of warm sand on to the skin and after a few minutes peristaltic movements of the stomach would often be distinctly felt.

(b) A very convenient condenser electrode can be made by filling a large flat-bottomed flask with salt water and passing a wire through an indiarubber cork fitted to its neck, the free end of the wire being connected to the resonator. With such an arrangement the effect is, perhaps, more exactly localised to the region it is desired to influence.

(c) The lead foil electrode is of such a size as to cove the whole gastric area; close contact is secured by interposing a layer of wet flannel between the metal and the skin. With this the patient usually feels scarcely anything over the area of application, and the quantity of the charge depends upon the electrostatic capacity of the individual. The effect of the application is in most cases highly invigorating.

The following are notes of the cases upon which the foregoing remarks are based.

CA.SE 1. - The patient was a middle-aged man, originally of active habits, and an enthusiastic golfer. A succession of severe mental shocks brought on a condition of profound

FIG. 1.

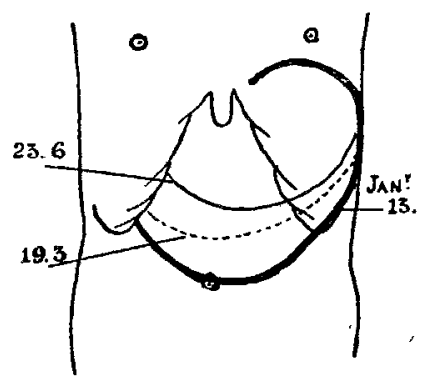

neurasthenia, fear of death from heart failure, pronounced agoraphobia, and obstinate dyspepsia with severe wandering pains. The circulation was slow and feeble but there was no organic heart trouble. Examination of the stomach on Jan. 13th, 1902, showed it to be enlarged to the level of the umbilicus (Fig. 1). It was never empty of food; the contents gave loud splashing on manipulation of the epigastrium. Electrical treatment by galvano-faradisation had been tried for some time without the slightest effect. Treatment by drugs had also failed. On Feb. 22nd high-frequency treatment was commenced and applied three times a week. By March 19th the stomach had contracted fully one and a half inches in the vertical direction and about a month later its size was practically normal. At this time no splashing could be evoked and the dyspeptic symptoms had practically disappeared. When seen on Sept. 10th this patient had lost practically all his troubles and had been able to resume his ordinary avocations in the beginning of July.

CASE 2. - The patient was a nervous woman, aged about 35 years, single, with sedentary habits. Her diet was too liberal. She was a frequenter of the various continental spas and health resorts. The abdominal walls were fat and flabby and the stomach was dilated to within an inch of the umbilicus. Splashing was readily evoked. After five weeks' treatment the stomach was nearly normal in size, but as it had been impossible in this case to prevent indiscretions in diet the permanent effect was less marked than in other cases and a complete cure cannot be claimed though there has been very marked improvement in her condition.

CASE 3.-The patient was an elderly man with an enormously dilated stomach which might be compared to a partially filled rubber water-bottle, the upper part being empty, and the fundus occupying a position quite two inches below the umbilicus. There were much splashing of contents and no enjoyment of life. There had been profound neurasthenia for many years. He had previously undergone all the ordinary methods of treatment without benefit. This patient did not improve as regards his gastric condition.

CASE 4.- The patient was an elderly man suffering from nervous breakdown consequent on mental overwork. The circulation was very feeble, the heart-beats seldom exceeding 45 or 50 per minute. The stomach was much dilated and the abdominal tissues were flabby. The appetite was fair, but his meals were generally followed by a feeling of weight in the epigastrium and cardiac embarrassment. He had occasional fainting attacks soon after meals. High-frequency treatment was commenced at the end of April, 1902, and was given on 12 occasions with decided improvement. The patient's average pulse-rate was now about 65 . His general condition had much improved and his meals were no longer followed by discomfort or pain. The stomach was much smaller. The patient writes at the beginning of October that the improvement has been fully maintained.

CASE 5.- The patient was a neurotic woman with dyspepsia, probably of nervous origin. The stomach was found to be dilated nearly to the level of the umbilicus, with splashing of the contents. Treatment applied daily for more than a week produced marked general improvement, disappearance of the local dilatation, \&c. This patient when seen on Sept. 10th showed only a very slight return of the dilatation and her husband-himself a medical man-said that there was now scarcely any trouble referable to the gastric condition.

CASE 6. - The patient was a business man, about 57 years of age. He had had flatulent dyspepsia for years. There were a nearly constant feeling of irritation referred to the lower end of the oesophagus and almost daily vomiting of mucous fluid. He had derived some benefit from general medicinal treatment, but on June 15th, when high-frequency treatment was commenced, the stomach was found to be distended to the level of the umbilicus and was tympanitic on percussion. The patient was almost afraid to eat on account of the discomfort which followed. After a week of treatment the symptoms had greatly improved and vomiting had ceased. The stomach had receded an inch in the vertical direction and there was much less gaseous distension. Treatment was subsequently applied three times a week and when last seen (Sept. 19th) the stomach was practically natural in size, digestion appeared to be carried out normally, and the patient said that he felt "quite another man."

CASE 7.-The patient was a man about 35 years of age. He was first seen on June 14th, 1902. He had been for years very careless as to diet, eating and drinking enormously and without discretion. He was a chronic neurasthenic dyspeptic, with the stomach greatly dilated, and loud splashing could be evoked with the greatest ease. He had frequent mucous vomiting and a constant feeling of oppression referred to the stomach. Treatment by drugs and dry diet had altogether failed and the only thing which had afforded relief was 
lavage of the stomach, which the patient had got into the habit of performing for himself three or four times daily. With some difficulty he was persuaded to discontinue the lavage and high-frequency treatment was given. After seven applications there was marked improvement, the patient having lost much of his depression and feeling less temptation to perform lavage. At the end of three weeks the condition of the stomach was almost normal, there being hardly any splashing at any time and the organ having gone up no less than three inches in the vertical direction. He then, contrary to advice, discontinued treatment and at the end of the holidays he wrote admitting dietetic indiscretions, followed by partial return of the trouble. When seen on Sept. 15th he was practically well.

CASE 8. - The patient was a man, aged 58 years, with 37 years of service in India, where he had escaped almost entirely the diseases incidental to a life in the tropics. $\mathrm{He}$ was first seen in October, 1901, on the eve of his return to India, after short leave at home. He had been suffering for 15 years from dyspeptic symptoms, which were gradually increasing in severity, and had then reached the stage of great acidity and heartburn, inability to sleep on this account, relief being obtained by vomiting a quantity of extremely acid fluid, after which he slept quietly till morning. Vomiting of this nature occurred two or three times a week and when it did not take place he had restless dis. turbed nights. His stomach was found to be greatly dilated and splashing was abundant. It was found that he had been in the habit during the greater part of his career in India of drinking large quantities of aerated water with his meals and before going to bed at night. It was not possible to put him on systematic treatment then, so near his return to duty in India, but he was advised to abstain from all fluids during meals and to assuage his thirst by drinking hot water three-quarters of an hour before each meal. In India during the cold weather of 1901 and 1902 he carried out this regimen with considerable benefit. His dyspepsia was considerably relieved and he vomited only twice in the six months from November, 1901, to April, 1902. He again came under observation here on April 30th. He still suffered much from acidity and flatulence, especially at night. His sleep was greatly disturbed on this account and he was anæmic and drowsy, especially after dinner, so much so that he could not keep awake for the prescribed period after that meal. He was depressed, lethargic, and almost hysterical. His stomach was greatly dilated, especially towards the cardiac end, and there were a wellmarked pyloric pouch descending almost to the right iliac crest; splashing was abundant. The necessity of continuing "dry" diet was again impressed on him and he was placed on the high-frequency electrical treatment on May 1st. His progress is shown in Fig. 2, in which the size and posi-

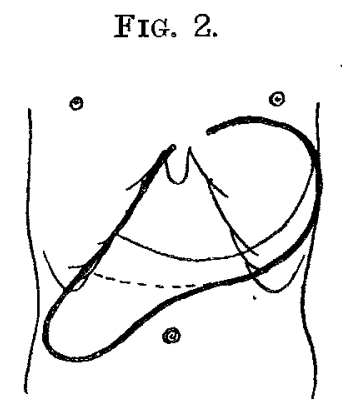

tion of the stomach are indicated by a broad line on April 30th, by an interrupted line on May 17th after 13 applications of the electricity, and by a thin line on June 4th, when his stomach was found to have practically assumed its normal size and position. From May 17th he took hæmatogen for his anæmia but no other medicine. On June 14th his stomach was found to have again dilated towards the cardiac end and there were some acidity and splashing attributable to his having partaken rather freely of forbidden things two days previously. Otherwise his indigestion had disappeared. He was in good spirits and had been able to go with pleasure to theatres, somnolence after dinner having ceased. On July 20th he wrote: "I am feeling better than I have felt for years. ...... I have had no acidity since the beginning of June." In August there was slight relaxation of the stomach and he received a week's treatment prior to returning to India.
CASE 9.-A man, aged 42 years, was first seen on Feb. 22nd, 1902. He had had 20 years' service in India, his duties requiring him to tour for eight months every year in the hot weather. He had had frequent attacts of malarial fever and dysentery in 1887 and 1895, and was invalided on account of gastro-intestinal troubles in 1896 and in 1898. His meals were of necessity very irregular while on duty and he drank large quantities of aerated water with food and at other times. He was again invalided in May, 1900, on account of muco-enteritis, abdominal pain, debility, emaciation, and insomnia. $\mathrm{He}$ had spent a great part of his leave on the continent and got considerable relief from "dry" diet, prescribed by Dr. Burger of Baden-Baden. In February, 1902, he was very depressed in spirits, suffering much from dyspepsia and insomnia. He believed his condition to be incurable. His stomach was much dilated, but no abnormal condition of the other organs could be detected beyond general intestinal ptosis and thickening of the cæcum. He was replaced on "dry" diet and massage of the abdomen was prescribed. After five weeks of this treatment there was little or no improvement except as regarded insomnia; he was able to sleep about four hours during the night. On April 5th he began the high-frequency treatment with but little improvement during the first week, and as he suffered from constipation he began to take a pill containing aloin and ferrous sulphate. At this time the stomach came as low as the umbilicus. On the 25 th it had receded one and a half inches in all directions and his symptoms were all relieved. He was bright, hopeful, and enthusiastic. On May 14th the stomach was three inches above the umbilicus, but the pyloric pouch still existed. He no longer complained of indigestion and be slept well. Gurgling rather than splashing could be elicited. The high-frequency treatment was intermitted for a few days and then continued three times a week. On the 24th the stomach was normal in size and he was free from all dyspeptic and neurasthenic symptoms. At the time of writing this patient's stomach remains of normal size and he expresses himself as being in better health than he has been for years. Fig. 3 shows the condition of h's stomach

FIT. 3.

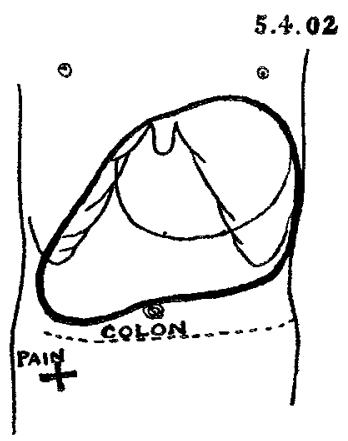

at the different dates mentioned. He is now only concerned regarding the uneasiness in the cxcum which seems to be the result of old dysenteric ulceration. The intestinal ptosis has disappeared.

CASE 10.-The patient was a man, aged 28 years. $\mathrm{He}$ was invalided in 1898 from West Africa on account of malarial cachexia and neuralgia after a "touch" of the sun. He spent 1899 in Malta, where he had several attacks of fever, but not Malta fever. He went to South Africa in February, 1900, and was invalided in December, 1901, on account of fever and neuralgia. He was first seen in February, 1902. He had not had fever since November of the previous year. His liver was painful on pressure and congested, but there was no enlargement of the spleen. He was very neurasthenic and irritable but he slept well. He suffered from morning retching and frequent attacks of hemicrania of the character of migraine. There were no malarial parasites to be found in the blood, but he was put on a course of arsenic, quinine, and Carlsbad salts, with small blisters over the liver. No great improvement followed this treatment and as he had a strong family history of gout and was, if anything, full-blooded it was thought that a course of treatment at Bath would do him good. He returned from Bath in the beginning of May with all his symptoms, except the hepatic congestion, aggravated. 
He had lost flesh and spirits, was easily fatigued, had constant morning nausea, and of ten vomited. His stomach was now found to be dilated. He was placed on "dry" diet and sent to recruit in the country. On May 13th he returned unimproved in any respect. After a test meal the stomach was found on the 14th to be dilated and splashing was freely elicited. On this date he was placed on the high-frequency treatment with the result that he lost all his symptoms, the nausea ceased after a few applications,

FIG. 4.

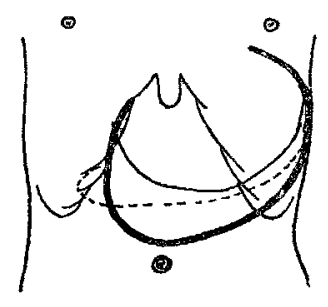

and the stomach had resumed its normal dimensions very nearly when he left London on the 28th, on which date, however, splashing was still audible. He has recently written that he continues free from dyspeptic symptoms. The dates on which the observations recorded in Fig. 4 were taken were May 13th, 22nd, and 28th.

CASE 11. - The patient was a man, aged 48 years, who had always been dyspeptic and who had suffered a good deal from malaria during a seven years' tour of service in India. $\mathrm{He}$ had enteric fever early in 1900 at Modder River, from which time his health completely broke down. He was first seen in August, 1901, when his stomach was found to be enormously dilated and his liver and spleen enlarged. In December, 1901, he was again seen, when it was found that an abscess was forming in the inner end of the left clavicle. This was opened in January. When next seen in April, 1902, a sinus was found leading down to a cavity in the bone, which was freely opened on the 30th and scraped under an anæsthetic, and the patient was placed on a "dry" diet. The abscess was believed to be post-t.yphoidal. The abscess - cavity filled up rapidly. On May 6th the condition of his stomach was as shown in Fig. 5

FIG. 5.

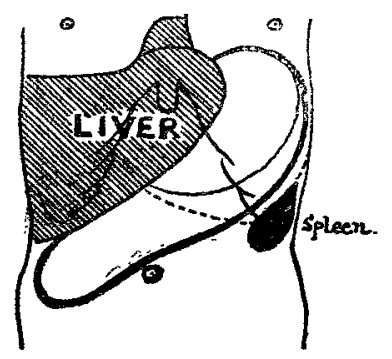

(broad line). It reached to the umbilicus and there was a well-marked pyloric pouch reaching to the right iliac crest, and the cardiac dilatation of the stomach passed as far to the left as the axillary line. The liver was enlarged and could be felt three fingers below the right costal arch. The spleen was large and leathery. He suffered much from acid dyspepsia; splashing could always be elicited; he was emaciated, neurasthenic, and depressed in spirits. The pyloric pouch was the first part of the dilatation to disappear, and with the contraction of this portion of the stomach his depression and most of his dyspeptic symptoms left him. He gained six pounds in weight while under treatment. The liver atso was reduced considerably in size, but no effect was produced on the enlargement of the spleen. By the middle of June the improvement in his health was so great that a medical board permitted him to return to duty in a home district. In the middle of July he wrote that he was well and "fit" in all respects and when last seen (Sept. 3rd) the improvement was in every way maintained.

CASE 12. - A man, aged 30 years, had good health till 1898, when he had Malta fever, since which time he had suffered continuously from dyspepsia of the character usual in atonic dilatation of the stomach-i.e., flatulence and acidity after meals and especially on going to bed, only relieved by vomiting. He had been under treatment for six weeks before being seen by us, the treatment baving been a "dry" diet and lavage of the stomach every second night. There had been no improvement under this treatment. When first seen the stomach reached to the umbilicus and there was abundant splashing at all hours of the day, but especially after dinner, when he had great distress from acidity and distension, only relieved by lavage. On June 4th, 1902, he was placed on high-frequency treatment, continuing the "dry" diet and lavage. In 18 days the stomach was normal in size and there was no splashing, but there was no improvement in his dyspeptic symptoms. Analysis of the contents of his stomach two and a half hours after dinner showed a complete absence of hydrochloric acid but abundant lactic and acetic acids; no butyric acid could be detected. After 17 applications the high-frequency current, the stomach being normal in size, was discontinued and the case was treated as one of hypochlorhydria from defective secretion, by means of acid given during and after meals, with marked improvement. The lavage has been gradually discontinued, the distress after dinner is much less, and the appetite is improving. There is now distinct indication of the presence of hydrochloric acid two and a half hours after a meal when no acid is given. The stomach remained of normal size three months after discontinuing the use of the high-frequency current. In this case there was very considerable tenderness in the epigastrium to the right of the middle line and it was at one time thought that there might be ulceration at the pylorus; but careful examination showed that this tenderness was hepatic and it has disappeared under repeated blisters.

CASE 13-A man, aged 32 years, who had been eight years in India. He had an attack of malarial fever four years ago, had had dyspepsia since 1898, and depression of spirits since 1899. He had enteric fever in May, 1901. He was first seen on May 7th, 1902. He was anæmic and complained of want of appetite, foul mouth and breath, fits of flatulent dyspepsia, pain in the stomach insomnia, and depression of spirits. His stomach was found to be dilated, reaching almost to the umbilicus, and splashing was abundant. He was placed on "dry" diet. On May 27 th he felt better in spirits and had less dyspepsia, but there was no improvement as regarded the insomnia and the size of his stomach; splashing was abundant. $\mathrm{He}$ was placed on high-frequency treatment, continuing the "dry" diet. On June 19th his depression, insomnia, and dyspeptic symptoms were gone, but there was still splashing and the stomach was enlarged, especially towards the pylorus. (He confessed that, contrary to orders, he had had salt fish at breakfast.) The electric treatment was continued and on July 7th he was well in all respects, the stomach was normal in size (Fig. 6), and there were no

FIG. 6.

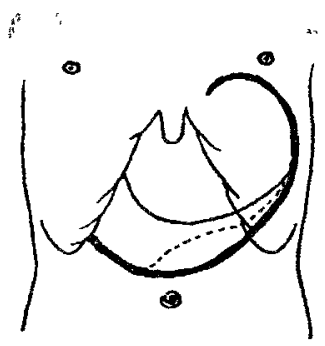

splashing, no dyspepsia, no insomnia, and no depression; he was still somewhat anæmic. We are informed that the improvement continues. Fig. 6 shows the condition of the stomach on May 27th, June 19th, and July 7th.

CASE 14.-A man, aged 22 years, who had scarlet fever when a child, followed by albuminuria up to 16 years of age. He had always been dyspeptic; had been two years in South Africa where he had diarrhoea for three or four months and was subjected to continuous mental strain. He had constant morning nausea and every other day vomited a very acid fluid about 6 A. M. with immediate relief; he had much flatulence at all times, had lost weight and nerve, and was afraid to ride a horse. He slept badly and was constantly dreaming and waking up. The stomach was much dilated and there was splashing. He had two or three loose motions daily. Treatment was commenced on July 14th, 1902. On the 23 rd he had had seven applications of high-frequency current; the morning sickness had gone and he had not 
romited since the beginning of the treatment. There was stili a little flatulence after meals; he had one rather loose motion daily; the nerves were better, but he still slept badly. The stomach was considerably smaller but the splash was distinct. On the 30 th he had had 13 applications. The stomach was normal in size and there was no splash; the digestion was good, the appetite was fair, and there was no acidity; the bowels were regular; he still slept badly, not getting to sleep till 12.30 or $1 \mathrm{~A}$. M. The treatment was stopped and he was advised to go to Ireland for a change of air.

CASE 15. - A man, aged 27 years. He had typhoid fever at Bloemfontein in May, 1900 ; he had a relapse and was in bed for six weeks. He had pneumonia in March, 1901. He was never in good health after the typhoid fever but only began to get distinct dyspepsia in January, 1902, accompanied by marked and increasing neurasthenia, so much so that he used to become hysterical and even sometimes to faint after any official strain. $\mathrm{He}$ was obliged on this account to throw up an important and congenial appointment. He was first seen on June 10th, 1902, when the principal dyspeptic symptoms were nausea in the morning and a sense of weight after meals with acidity at times. The neurasthenia was extreme. The stomach was much dilated, especially towards the pyloric end, and there was abundant splashing. Some delay oocurred in getting him relieved of his official duties and he was not placed on the high-frequency treatment till June 30th. During this time he was on a "dry" diet, but there was little or no im. provement in his local or general condition. On July 12th his stomach was as indicated by the interrupted line in Fig. 7;

FIG. 7.

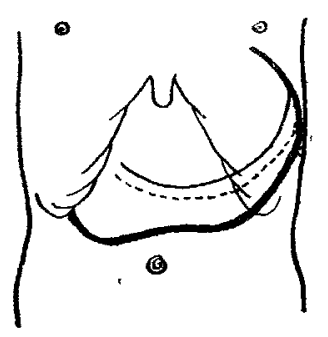

after seven applications of the high-frequency current his dyspeptic symptoms were practically gone and there was no splashing. This symptom disappeared after the third application and he was much less nervous. On the $17 \mathrm{th}$ his stomach was natural in size, his digestion was normal, but he was still conscious of an occasional splash on going to bed. On the 30 th his stomach and digestion were, and had been for some time, normal and he went to Scotland to get rid of the remaining neurasthenia. In this case each application of the current after the third was followed by severe frontal headache which lasted for from five to seven hours, unrelieved by phenacetin. On Oct. 11th this patient's gastric eondition was still satisfactory.

CASE 16.-This patient was a man who had been for 30 years in India. He had not suffered much from fever except during the last two years, when he had much "low fever." Digestion had been weak for 20 years and, judging by his own feelings, had been delaved eight or nine hours. On July 3rd, 1902, he was very emaciated and anæmic. His weight was 8 stones $7 \frac{3}{4}$ pounds. He was not greatly roubled with indigestion; he was very sleepy after meals; he had no appetite. The stomach was much dilated, as low as the umbilicus, with well-marked pyloric pouch extending beyond the right nipple line. There was much splashing. He had pyorrhoea alveolaris. Treatment was commenced on July 4th, 1902. On the 10th there was very little improvement but on the 14th his weight was 8 stones $10 \frac{1}{4}$ pounds. On the 17 th the stomach was normal in size and position. He was much less sleepy after meals. The headaches were nearly gone and his appetite was better. His weight was 8 stones $11 \frac{1}{2}$ pounds. On the 23rd he was not sleepy after meals; he had no great appetite but enjoyed his food and was gaining weight. On the 30th improvement was maintained; his weight was 9 stone $-3 \frac{1}{2}$ pounds. On August 6 th he felt quite a different man; his stomach kept normal; his weight was 9 stones $9 \frac{1}{2}$ pounds.

CASE 17.-A man, aged 45 years. He had had enteric fever 14 years ago and had never felt quite well since; he was dyspeptic, flatulent, and nerrous for 18 months and had never been able to drink tea since then-it always caused great flatulence and depression. With that exception he had fairly good health in India for five years. He had malarial fever in 1895 and there were crescents in his blood up to 1899. He went to South Africa in 1900 and was on trek, except when shut up in Reitz, where he could not get sufficient food. There he became very unwell, could not digest, and was invalided for enlarged liver and megrim. He was not dyspeptic previously to suffering from enteric fever. $\mathrm{He}$ had been doing work since October, 1901, but only got abont four hours' sleep at night; there was no heartburn but much discomfort and bad taste in the mouth. On May 20th, 1902, the stomach was much dilated, reaching the umbilicus, with loud and abundant splashing all over the dilated organ; the liver was enlarged and tender. After three weeks' treatment by diet there was no improvement and he was placed under treatment by high-frequency currents. The stomach responded and receded on each application, so that in three weeks there was marked diminution in size, with much improvement in his general condition. He was less tired, slept better, and was more cheerful, but there was a constant tendency to relaxation. On June 30th he ate some stale fish and had a bad attack of dyspepsia, with much flatulent distension ; discomfort, borborygmi, and sleepless ness returned. On July 2 nd the stomach was found to have relaxed and its lower border was within an inch of the umbilicus and there was much splashing. The treatment was continued and on the 9 th the stomach was found to be normal in size; there was little or no splashing and he was in all respects better. His weight increased while under treatment by more than a stone. It is very doubtful whether this patient can be considered cured, though he is vastly improved, and when seen on August 11th he was full of energy for work and described himself as only rarely feeling any gastric discomfort.

\section{NOTES ON A NEW SYSTEM OF TREAT- MENT IN PULMONARY PHTHISIS.}

BY DUNCAN TURNER, M.R.C.P. LOND., L.R.C.S. EDIN., HONORART CONSULTING PHYSICTAN TO THE SANATORIUM FOR CONSUMPTIVES, ECHUCA AND MACEDON, NEAR MELBOURNE, VICTORIA, AUSTRAIIA.

MaNY improvements have been made in the treatment of phthisis, but much still remains to be done, for high altitudes, aseptic air, and generous diet are often of no avail, while many patients are unable to take advantage of these methods on account of the expense and various other obstacles. The following notes give the results of observations made partly in private practice but principally in the Sanatorium for Consumptives. Mount Macedon, near Melbourne.

For many years I have been convinced of the utility of massage and electricity in restoring tone to the system and improving nutrition generally; and having on many occasions observed the usefulness of rubbing with cod-liver oil in the case of children suffering from tuberculosis of the bowel, as recommended by the late Sir J. Y. Simpson, I determined to make trial of electricity and massage im ordinary tuberculosis of the lung as met with in adults. After using this treatment for some time it occurred to me that many of the remedies employed in phthisis might perhaps be administered through the skin as well as through the stomach and possibly even with greater advantage. Cod-liver oil, creasote, and guaiacol are by many persons found to be nauseous and productive of indigestion, but after six or seven years' experience I am confident that all the physiological effects of these remedies can be obtained by external use, the combination employed by me being a mixture of four drachms of creasote or guaiacol, one drachm of oil of citronelle, and cod-liver oil to make four ounces; the oil of citronelle is added merely to disguise the smell of the creasote and cod-liver oil.

The oil-massage treatment has now been used for three seasons at the Sanatorium for Consumptives at Moun Macedon and each season with better results. The sanatorium had been going on for some years before this, relying on pure air and guod food as the only means to restore 